\title{
Improving English reading for EFL readers with reviewing kit-build concept map
}

\author{
Banni Satria Andoko ${ }^{1,2^{*}}$ D, Yusuke Hayashi ${ }^{1}$, Tsukasa Hirashima ${ }^{1}$ and Atiqah Nurul Asri ${ }^{2}$
}

\author{
* Correspondence: ando@lel. \\ hiroshima-u.ac.jp \\ ${ }^{1}$ Department of Information \\ Engineering, Hiroshima University, 1 \\ Chome-3-3-2 Kagamiyama, \\ Higashihiroshima, Hiroshima \\ 739-0046, Japan \\ ${ }^{2}$ Department of Information System, \\ State Polytechnic of Malang, Jl. \\ Soekarno Hatta No.9, Jatimulyo, Kec. \\ Lowokwaru, Malang, East Java \\ 65141, Indonesia
}

\begin{abstract}
Reading comprehension for English as foreign language (EFL) students is crucial. Available information is mostly written in English, which becomes a problem for students from non-English-speaking countries. Such students should master English first in order to understand the information. This research offers a method to improve English reading with the help of the kit-build concept map as a graphical strategy and an additional function called source connection to facilitate EFL readers in reviewing their concept maps as the representation of their understanding. In this study, an English teacher in an Indonesian university practically used this system in the English class of second-year undergraduate students as EFL readers and tested the effectiveness of it. Results confirm that students who use the kit-build concept map with the source connection function show better performance in English reading compared with those who employ the traditional summarization method.

Keywords: Concept map, EFL, Kit-build concept map, Reading assistance
\end{abstract}

\section{Introduction}

Reading is one of the important activities to obtain knowledge or information. In other words, reading is one of the gateways of knowledge. It is an active and fluent process involving the readers and the reading materials in building meaning (Anderson, 2003). It is also noticed as an active task where readers are making selection from a range of words, derive from the text and the situational context that are constructing a model of meaning that reflects, more or less the same, the meaning designated by the writer (Dole, Duffy, Roehler, \& Pearson, 1991). Bowey (2005) said that the ultimate goal of reading is understanding a continuous text. Word recognition becomes the foundation of reading, and all other processes are dependent on it (Snowling \& Hulme, 2005).

Reading comprehension in English of native readers and English as foreign language (EFL) readers is different. Understanding a reading material for EFL readers requires more effort because they are more attached to texts or required to read the same texts more frequent than native readers (Bernhardt, 1986; Bernhardt \& Kamil, 1995). For some EFL readers, reading comprehension in English can be a challenging activity because they may understand each word separately, but when the words are combined into meaningful ideas, they often failed to understand the meaning as it should (McNamara, 2007).

A popular strategy for reading comprehension is a graphical strategy. The underlying principle of graphical strategies is converting linear textual statements into a nonlinear

(c) The Author(s). 2020 Open Access This article is distributed under the terms of the Creative Commons Attribution 4.0 International License (http://creativecommons.org/licenses/by/4.0/), which permits unrestricted use, distribution, and reproduction in any medium, provided you give appropriate credit to the original author(s) and the source, provide a link to the Creative Commons license, and indicate if changes were made. 

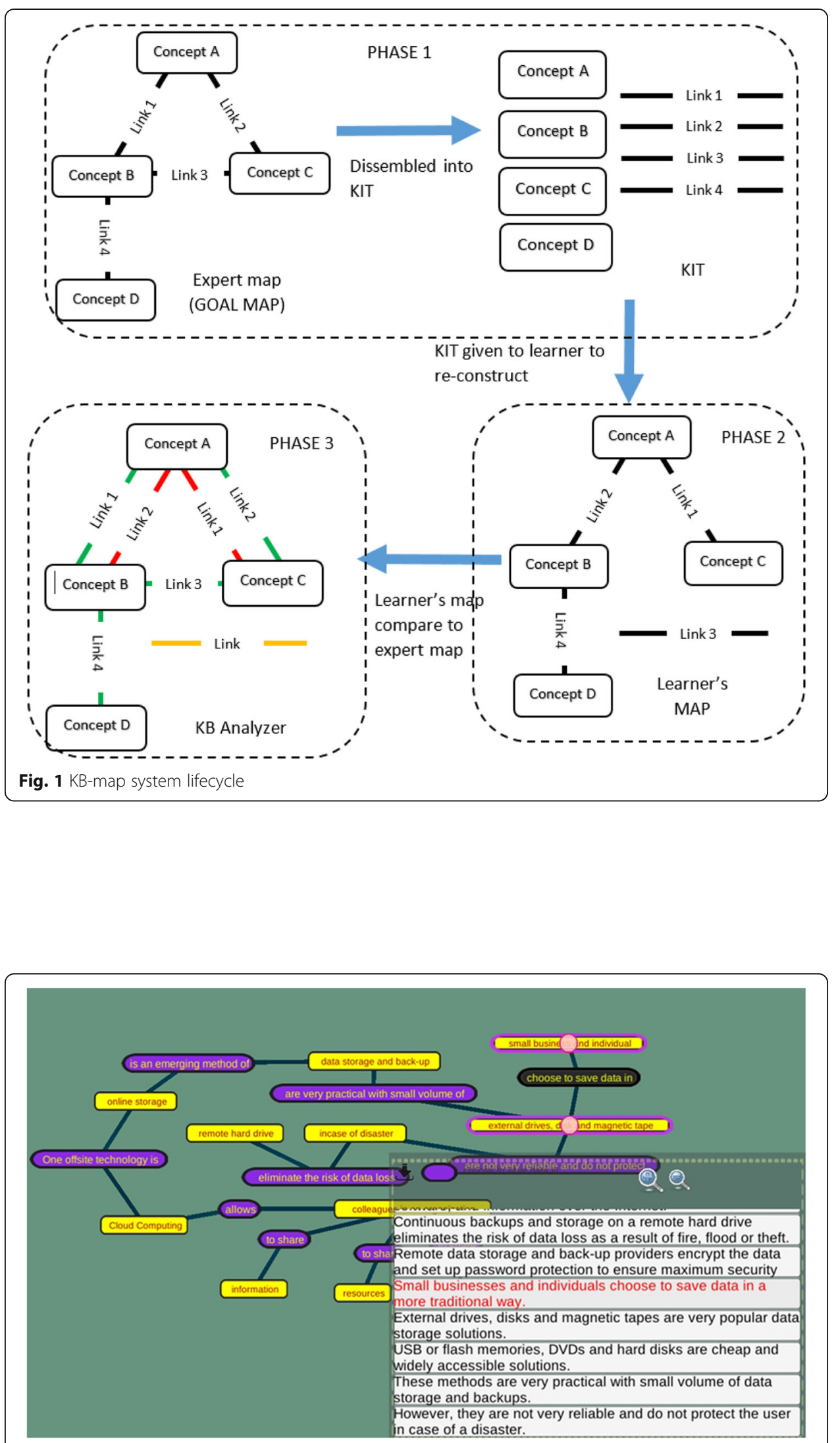

Fig. 2 Example of kit-build with the source connection 
Table 1 Mean of the pre-test score

\begin{tabular}{lllllll}
\hline Group & N & M & F & Avg. age & Mean & SD \\
\hline Summarizing method (C) & 78 & 58 & 20 & 19.98718 & 30.1667 & 11.6423 \\
Kit-build (E1) & 77 & 44 & 33 & 19.75325 & 30.5325 & 8.5480 \\
Kit-build with source-connection (E2) & 77 & 48 & 29 & 19.94805 & 30.0390 & 10.6418 \\
\hline
\end{tabular}

graphic presentation (Chang, Sung, \& Chen, 2002). The tree structure that appears after the construction has a similarity to the macrostructure of the text, and it is easy to retain and retrieve (van Dijk \& Kintsch, 1983). Graphical strategies made by the learners themselves can promote autonomous learning and enhance the depth of learning, but these will be time consuming for training. This kind of task will also demand effort and can usually lead to a cognitive load and negative affect in learning outcomes (Chang, Sung, \& Chen, 2001). To be able to construct it, learners must first determine important concepts and make the relations between the concepts. Moreover, the whole structure will become summarized information in the shape of an information tree, which could be one of the reasons why graphical strategies are successful in reading comprehension.

Using an expert-generated map could help learners by presenting the macrostructure of the text in the form of a graphic representation and could help save time and give a well-defined graphic organization that can serve as a preview of the reading material outline structure (Chang et al., 2002). However, this kind of environment sometimes can put learners into passive learning where they cannot think creatively (because they cannot create their own map) and may eventually undermine their learning performance (Baron \& Schwartz, 1984).

Kit-build concept mapping (KB-map) is an active learning method with expertgenerated maps (Hirashima, Yamasaki, Fukuda, \& Funaoi, 2015; Yamasaki, Fukuda, Hirashima, \& Funaoi, 2010; Yoshida, Sugihara, Nino, Shida, \& Hirashima, 2013). In the KB-map method, learners generate concept maps from the components of an expertgenerated map instead of generation from scratch as the original concept mapping method. This method has the same efficiency as the original method for comprehended information in a comprehension test taken just after reading (Funaoi, Ishida, \& Hirashima, 2011). The KB-map assessment method is automated, and its validity for evaluating the understanding of learners has been confirmed (Wunnasri, Pailai, Hayashi, \& Hirashima, 2018). In addition to the one-on-one comparison, overlapping the learner maps as the representation of the aggregated understanding of learners is possible. Comparing the overlapped maps with the expert-generated map, the teacher can analyze the trend and errors of learner understandings in the class. The analysis is helpful for the teacher to provide feedback to the learners (Pailai, Wunnasri, Yoshida, Hayashi, \& Hirashima, 2017; Yoshida et al., 2013).

Table 2 Analysis of covariance (ANCOVA) of pre-test scores

\begin{tabular}{lllll}
\hline Source & SS & Df & F-ratio & $p$ value \\
\hline Age & 287.4 & 1 & 2.7353 & 0.09954 . \\
Group & 0.0 & 2 & 0.0001 & 0.99988 \\
Age:group & 139.0 & 2 & 0.6616 & 0.517029 \\
Residuals & 23743.4 & 226 & & \\
\hline
\end{tabular}

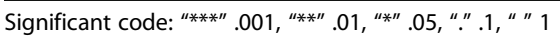




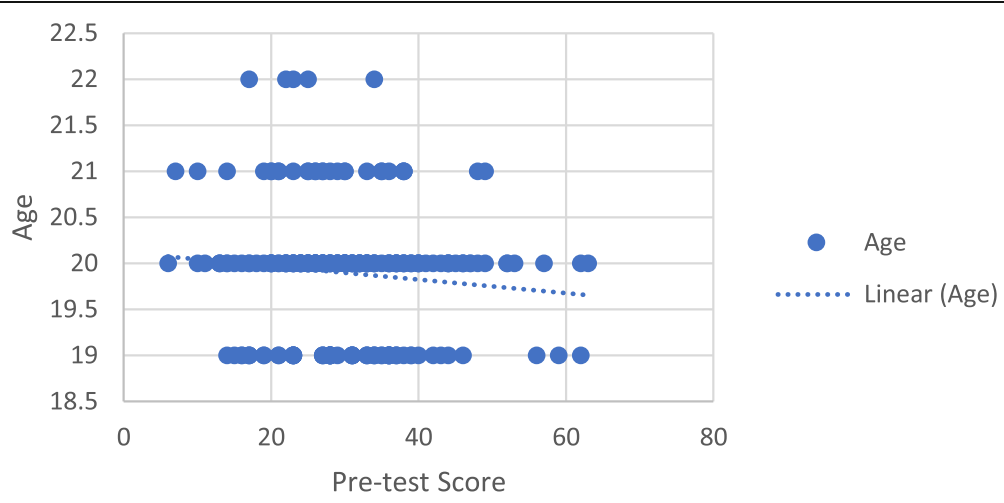

Fig. 3 Correlation between age and pre-test score

In a classroom situation, the teacher can help the learners to review their understanding. However, teachers have a time limitation, and different types of reading comprehension problems exist. Teachers must encourage learners to solve problems by themselves. To promote the self-problem-solving activity, this research proposes a new function called source-connection in the kit-build concept map. It will facilitate learners to review their concept map, and hopefully, they will be able to find the errors in the proposition and fix them by themselves. Thus, this study aims to examine the effect of the KB-map with the source-connection function for EFL readers. The study hypothesizes that the KB-map with the source-connection function facilitates EFL readers to confirm the validity of the concept maps they have generated and obtain a better understanding of the reading materials than another method like summarization and just KB-map. To address it, the research question will be as follows: Can the kit-build concept map with the source connection groups overachieve immediate and delay test scores compared with the traditional summarization method and usual kit-build groups?

\section{Literature review}

\section{Reading comprehension strategies}

In reading, novices and experts use their background knowledge, some existing cues in the text, and the situational contexts that are combined into a kind of a meaning model constructor of the text. Novice readers sometimes can act like experts when they are given a text and task where they have the appropriate knowledge. On the contrary, expert readers can become novices when they are exposed to ambiguous texts or new information. Accordingly, those two important characteristics of readers, namely, the knowledge that they have and the strategies that they use to foster and maintain understanding, play important roles in distinguishing between the old and new views of comprehension.

Table 3 Flesch Grade Level formula result for each material

\begin{tabular}{llll}
\hline Reading material & Grade level & Reading level & Reader's age \\
\hline Data Storage & 10 & Fairly difficult to read & 14-15 years old (9th to 10th graders) \\
Channel of Communication & 11 & Difficult to read & 15-17 years old (10th to 11th graders) \\
Banana & 12 & Difficult to read & 17-18years old (12th graders) \\
\hline
\end{tabular}




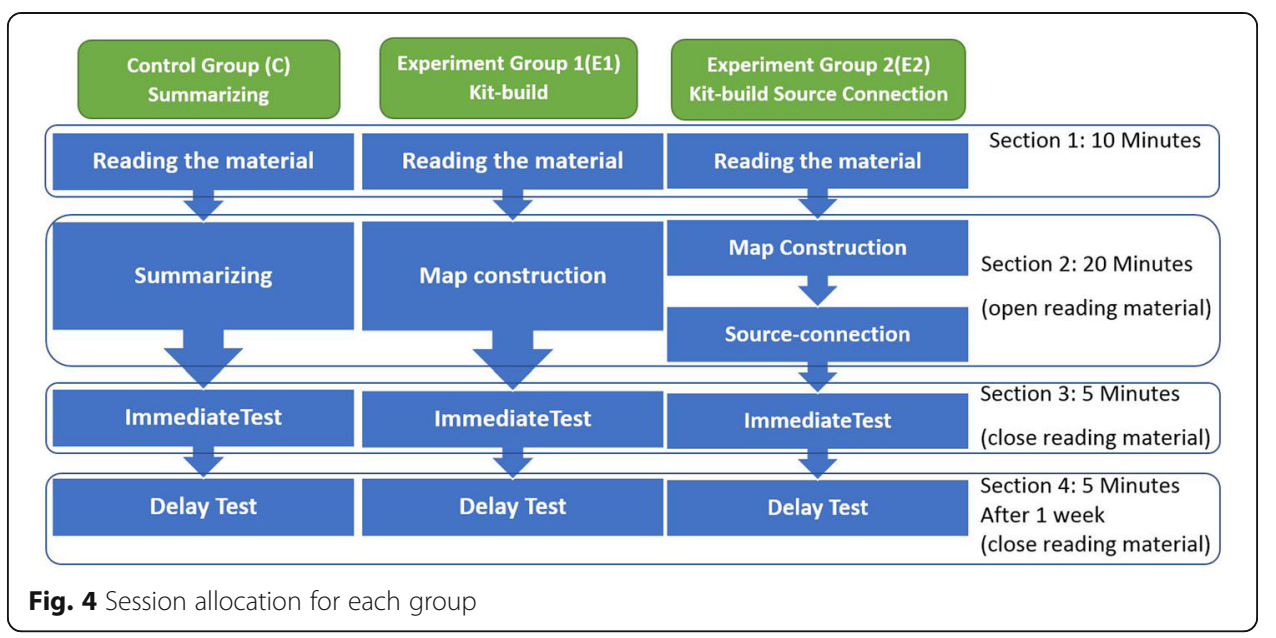

On the one hand, strategies emphasize reasoning and reasoning and critical abilities can be used when constructing and reconstructing the expanding meaning of the text. On the other hand, skills tend to be related to a low level of learning and thinking. Moreover, the strategies and skills of readers are also different in terms of awareness. Strategies signify metacognitive awareness. Expert readers can reflect what they do while reading (Baker \& Brown, 1984), and they have the awareness to judge and evaluate their understanding. This awareness tends to lead to regulation and repair. In the traditional skill curriculum, presumably, by doing a repeated practice and drill, readers would directly use the skills they have learned to everything they read. No room for neither intentionality nor consciousness will emerge in using these skills; in short, skills will be used automatically or unconsciously.

\section{Comprehension monitoring}

Comprehension monitoring is an ongoing activity that evaluates and regulates the understanding of an individual from a written (or spoken) text (Baker, 1984; Baker \& Brown, 1984). Furthermore, comprehension monitoring is defined as a metacognitive

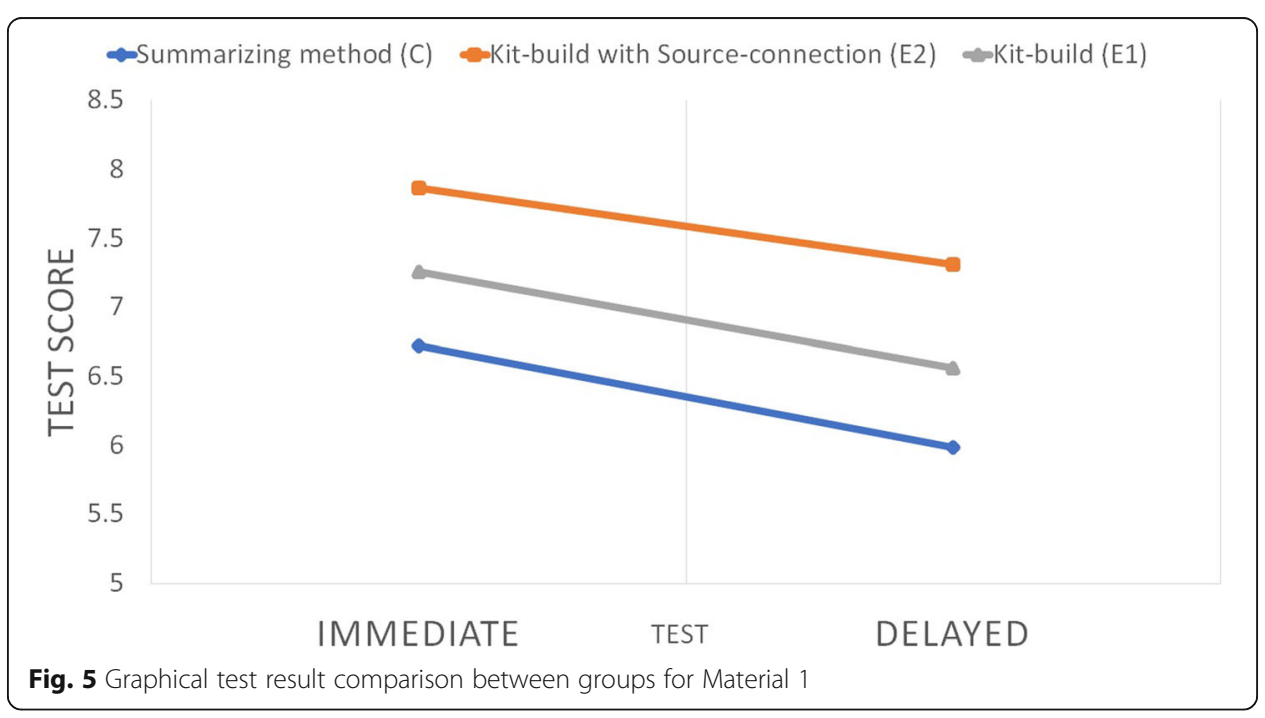


Table 4 Mean of the immediate and delay tests of Material 1 in all groups

\begin{tabular}{llllll}
\hline Group & N & Mean immediate & Mean delay & SD immediate & SD delay \\
\hline Summarizing method (C) & 78 & 6.7308 & 6.0000 & 1.9585 & 2.1861 \\
Kit-build (E1) & 77 & 7.2468 & 6.5844 & 1.5145 & 1.6650 \\
Kit-build with source-connection (E2) & 77 & 7.8701 & 7.3117 & 1.2392 & 1.6484 \\
\hline
\end{tabular}

process affected by person, strategy, and task variables (Wagoner, 1983). This activity encourages students to become active during the process of understanding in reading the section (Casanave, 1988). Comprehension monitoring becomes one of the strategies used in reading comprehension because of its ability to enhance learning.

Moreover, comprehension monitoring consists of two parts of processes: (1) being aware of the quality and degree of the understanding of an individual and (2) knowing what to do and how to do it when one finds a comprehension failure. Expert readers are better than the novice ones when using the available resources like looking back to the text to solve the problem. Alessi, Anderson, and Goetz (1979) claimed that the lack of knowledge in the consequence of deficits or losing information could be restored almost completely when using an induced look-back strategy on the part of college students. They also found that the monitor of a good reader not only occurs in comprehension monitoring but also becomes the key to restoring the lost comprehension. Monitoring takes a big role to differentiate between expert and novice readers.

\section{Graphic strategies}

A graphic strategy is a common approach to be used in reading strategies. It can be used as a preview phase before reading, throughout the reading process, and at the phase after reading (Dowhower, 1999). The whole text structure and the interrelations among concepts are shown in the graphic with a visual method that provides readers a clear and prime understanding of what is being read (Robinson, Katayama, \& Fan, 1996). One of the graphic strategies is the concept map (Novak, 1990).

Concept mapping offers a graphic strategy that provides readers with new approaches to reading that are different from traditional (Chang et al., 2002) and also lets learners organize information through visual aids (Liu, Chen, \& Chang, 2010). That kind of action can stimulate their metacognitive awareness (Chang et al., 2002). However, concept mapping can also promote some difficulties; they can be idiosyncratic in terms of

Table 5 Analysis of covariance (ANCOVA) type II SS result for Material 1

\begin{tabular}{lllll}
\hline Source & SS & Df & F-ratio & $p$ value \\
\hline Pre-test & 198.811 & 1 & 75.6051 & $<0.001^{* * *}$ \\
Age & 0.185 & 1 & 0.0702 & 0.791 \\
Group & 117.841 & 2 & 22.4066 & $<0.001^{* * *}$ \\
Pre-test: age & 0.338 & 1 & 0.1285 & 0.720 \\
Pre-test: group & 20.043 & 2 & 3.8111 & $0.023^{*}$ \\
Age: group & 16.284 & 2 & 3.0964 & $0.046^{*}$ \\
Pre-test: age : group & 0.517 & 2 & 0.0983 & 0.906 \\
Residuals & 1188.578 & 452 & & \\
\hline
\end{tabular}

Significant code: " ${ }^{\prime * * * *} .001, "$,**". 01, , "** .05, "." .1, " " 1 
Table 6 Analysis of variance (ANOVA) type II result for immediate test and pre-test

\begin{tabular}{|c|c|c|c|c|}
\hline Source & SS & Df & F-ratio & $p$ value \\
\hline Group & 50.10 & 2 & 10.9877 & $<0.001^{* * *}$ \\
\hline Age & 0.45 & 1 & 0.1986 & 0.6563 \\
\hline Pre-test & 66.38 & 1 & 29.1169 & $<0.001^{* * *}$ \\
\hline Residuals & 517.51 & 227 & & \\
\hline
\end{tabular}

design that they require some expertise to learn, and because of their complexity, they may not always assist memorability (Davies, 2011).

A previous study conducted by Liu et al. (2010) on concept maps on EFL for college students involved 192 freshmen who were divided into two groups. Their experiment used nine articles from English magazines as the reading material, and they used the reading test provided by the magazines for evaluating the students. The reading test consists of 22 reading comprehension questions, and the test duration is $60 \mathrm{~min}$. They also used a revised questionnaire from the questionnaire of Yang (2003). Their experiment was conducted for 10 weeks; each class was allocated $2 \mathrm{~h}$ a week. Before the experiment, each group was given a pre-reading test. They classified the students into good and poor readers on the basis of the test. The result confirmed that the concept mapping for the reading strategy was more effective than that for the traditional reading strategy to improve the reading comprehension of poor readers, and for good readers, the learning effect between the experimental and control groups was not always found. They concluded that concept mapping helps students analyze the structure of an article, especially for poor readers.

Chang et al. (2002) conducted a study using a concept map with an expert-generated map. They also argued that using an expert-generated map might reduce teacher workload and help avoid student cognitive overload. In their study, the scaffolding group used the expert-generated map employed as a scaffolding instruction with spatial learning strategies. The structure of the expert-generated map was given to the learners as a kind of skeleton structure, but the text in some node was removed so the learners must fill the text by choosing the correct text from the provided list of words. The scaffolding was a teaching method that provides different degrees of assistance for a learner according to his/her progress. In the beginning, the learners were provided with a complete expert map, so they could analyze the relationship between the map and the reading material. If their performance improved (the percentage of correct propositions increased compared with that in the previous map), then the expert-generated map would be given as an incomplete map and finally without a map at all (an empty canvas

Table 7 Analysis of variance (ANOVA) type II result for immediate test, delayed test, and pre-test

\begin{tabular}{lllll}
\hline Source & SS & Df & F-ratio & $p$ value \\
\hline Group & 14.77 & 2 & 3.5156 & $0.3137^{*}$ \\
Age & 0.02 & 1 & 0.0076 & 0.93046 \\
Immediate test & 176.37 & 1 & 83.94 .61 & $<0.001^{* * *}$ \\
Pre-test & 40.03 & 1 & 19.0510 & $<0.001^{* * *}$ \\
Residuals & 474.82 & 226 & & \\
\hline
\end{tabular}

Significant code: "**** $.001, "$ "**". $01, "$ "**" .05, "." .1, " " 1 
Table 8 The combined mean for Material 1

\begin{tabular}{llll}
\hline Group & $n$ & Mean & SD \\
\hline C & 156 & 6.3654 & 2.1010 \\
E2 & 154 & 7.5909 & 1.4802 \\
E1 & 154 & 6.9156 & 1.6207 \\
\hline
\end{tabular}

like the original concept map). Another use of the expert-generated map in their study was a map-correction approach. In this method, the learners were provided with $40 \%$ of the incorrect node interrelation of the expert-generated map according to the reading material. The learners were asked to correct the node contents without fixing the map structure. Chang et al. (2002) included 126 fifth grade elementary school students. They divided the group randomly into four (scaffolding-map, map-correction, mapgenerated, and control groups): one control group and three experimental groups. In the control group, students were asked to read and make a summary from the article provided for the experiments. Two out of three experimental groups used an expertgenerated map. This experiment was conducted for 7 weeks using reading comprehension and summarization test as covariates. The experiment result corroborated that the map-correction group was improved more than the map-generation and control groups. The map-generation map score was not so different from that of the control group. In contrast to the map-generation group, the map-correction group outperformed the control group in all tests. Chang et al. (2002) also suggested that using scaffolding or map-correction strategies may be a potential approach in a concept map.

\section{Kit-build concept map}

The KB-map method is a kind of concept mapping method. In terms of understanding measured by the comprehension test right after the reading process, the KB-map has been proven to have the same efficiency as a normal concept mapping method (Alkhateeb, Hayashi, \& Hirashima, 2013). Moreover, the KB-map has prime efficiency in terms of recalling information in the text. The KB-map is a closed-end concept map. It means that the students cannot create their concept and link since it is provided by the system from the dissembled expert map. This kind of approach may reduce teacher workload and learning complexity. However, sometimes, learners make an incorrect proposition because of their capabilities on processing texts, and it would be more difficult if they have some time limitation to complete all the processes (classroom situation). The closed-end approach can also be easily taken into the automatic diagnosis of the constructed map of the learners because it has the same component as the expert map. Therefore, finding a difference among them from the diagnosis result form will be feasible. Using the provided component, learners can construct a map limited

Table 9 Holm's sequentially rejective Bonferroni procedure results for Material 1

\begin{tabular}{llllll}
\hline Pair & Diff & $t$ value & Df & $p$ & \\
\hline C-E2 & -1.2255 & 4.9591 & 229 & $<0.001$ & $C<E 2$ *** \\
E1-E2 & -0.6753 & 2.7240 & 229 & 0.0139 & $C<E 1^{*}$ \\
C-E1 & -0.5502 & 2.2264 & 229 & 0.0270 & $C<E 1^{*}$ \\
\hline
\end{tabular}

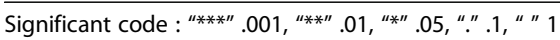




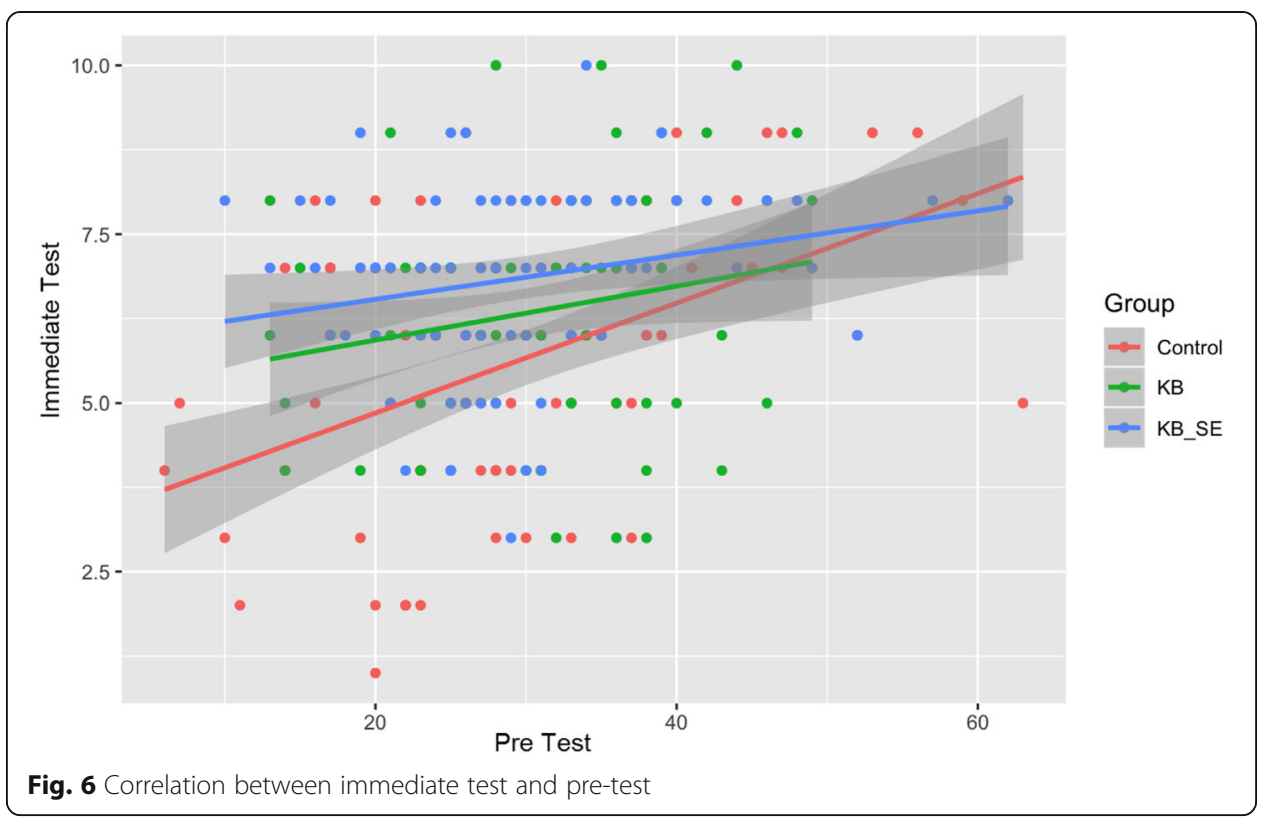

by the component itself, unlike the concept maps where learners can freely create the component and the map by themselves.

Several main phases are available in the KB-map: the first phase is goal map building, the second phase is learner map building, and the third phase is a KB analyzer. Goal map building is a phase where the instructor or the teacher or the expert will construct the map from the information source or reading material, and this map will then be called a goal map. Thereafter, the goal map will be dissembled into parts or components consisting of nodes and links called kit. Learner map building is a phase where the learners will reconstruct the map from the provided node and link, and the constructed map by the learners will be called learners' map. In this reconstruction process, learners can only reconstruct a proposition into the map from the provided link and node, and they cannot create any new links or nodes. This process is different from the

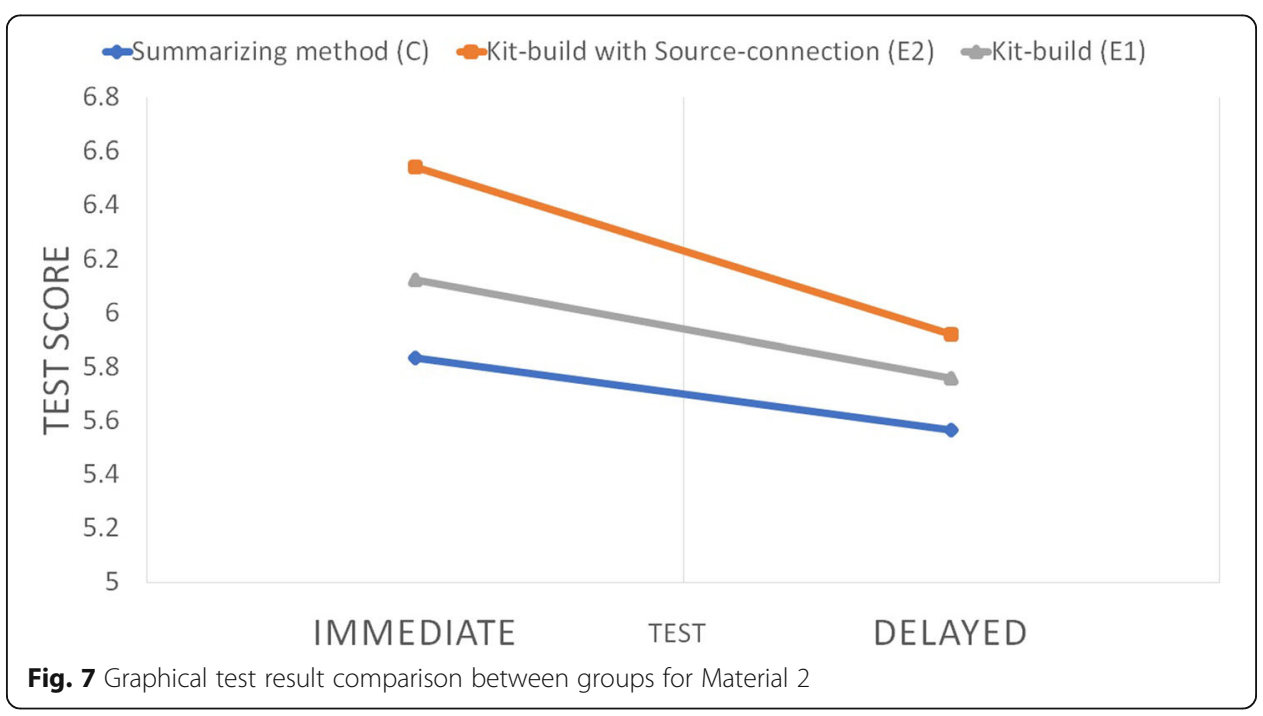


Table 10 Mean of the immediate and delay tests of Material 2 in all groups

\begin{tabular}{llllll}
\hline Group & $\mathrm{N}$ & Mean immediate & Mean delay & SD immediate & SD delay \\
\hline Summarizing method (C) & 78 & 5.807692 & 5.564103 & 1.644019 & 1.592105 \\
Kit-build (E1) & 77 & 6.116883 & 5.779221 & 1.235165 & 1.429238 \\
Kit-build with source-connection (E2) & 77 & 6.545455 & 5.922078 & 1.153318 & 1.285202 \\
\hline
\end{tabular}

study conducted by Liu et al. (2010) where students were not provided with anything; hence, they needed to create their own node and link as the original concept of concept map. The process is also different from that conducted by Chang et al. (2002, 2001), where students from a scaffolding method group were provided with a complete expert-map structure with an empty text in some nodes and links; thus, the students needed to fill the text by choosing it from the list provided by the system. The KB analyzer phase is where the teacher or the instructor or the expert will check the learners' map compared with the goal map. The analysis will automatically be provided by the system by using the exact matching method. The exact matching method compares each proposition on the goal map and learner's map (Fig. 1).

Alkhateeb et al. (2013) conducted a study by using the kit-build concept map compared with the selective underlining strategy to support reading comprehension in EFL. The selective underlining strategy is where students organize what they have read by highlighting, underlining, or selecting the phrases, words, key concepts, and sentences that are important or central to understanding the reading. In this experiment, eight third grade Japanese students of Information Engineering Faculty were involved. Their Test of English for International Communication (TOEIC) score was between 430 and 625. The students were divided into two groups. They were divided equally on the basis of the aptitude pre-reading test. The experiment was conducted six times by using six different reading materials. The result was measured by using an immediate and delayed test and confirmed that the KB-map had a better effect on recalling the comprehended information 2 weeks after being used.

\section{KB map with source connection}

To improve the process of learning during map construction, we have added the source connection function to the KB-map. This function aims to facilitate learners to make confirmation of their understanding in the form of learners' map with the reading

Table 11 Analysis of covariance (ANCOVA) type II SS results for Material 2

\begin{tabular}{lllll}
\hline Source & SS & Df & F-ratio & $p$ value \\
\hline Pre-test & 14.40743 & 1 & 7.299 & $0.007^{* *}$ \\
Age & 0.00112 & 1 & $5.68 \mathrm{e}-4$ & 0.981 \\
Group & 23.75992 & 2 & 6.019 & $0.003^{* *}$ \\
Pre-test: age & 0.91293 & 1 & 0.463 & 0.497 \\
Pre-test: group & 6.10558 & 2 & 1.547 & 0.214 \\
Age: Group & 8.93523 & 2 & 2.263 & 0.105 \\
Pre-test: age: group & 0.51871 & 2 & 0.131 & 0.877 \\
Residuals & 1188.578 & 452 & & \\
\hline
\end{tabular}

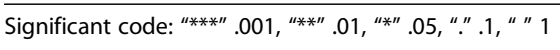


Table 12 Analysis of variance (ANOVA) type II result for immediate test and pre-test

\begin{tabular}{|c|c|c|c|c|}
\hline Source & SS & Df & F-ratio & $p$ value \\
\hline Group & 21.17 & 2 & 5.7242 & $0.003756^{* *}$ \\
\hline Age & 1.28 & 1 & 0.6910 & 0.406711 \\
\hline Pre-test & 3.60 & 1 & 1.9451 & 0.164475 \\
\hline Residuals & 419.75 & 227 & & \\
\hline
\end{tabular}

material. It prompts learners to confirm each proposition by making a connection between a proposition and a specific sentence of the reading material. After the connection is made, the color of the proposition will be changed into black, and the selected text will also be changed into red (Fig. 2).

\section{Methods}

\section{Participants}

In this research, 232 sophomore students of the Information Technology Department at State Polytechnic in Indonesia were involved. Their ages range from 19 to 22 . Their first language is Bahasa Indonesia. They were divided into three groups: one control group and two experimental groups. To ensure that each group had the same level of reading comprehension, the reading comprehension pre-test was conducted before the experiment shown in Table 1. It was used as a basic guide to create the three groups. We also considered the students' age to check the equality among the groups. Several studies found that age differences in knowledge effect on various outcomes, specifically in terms of memory performance. A study by Morrow, Leirer, Altieri, and Fitzsimmons (1994) found that age differences between pilots were eliminated on a task that provided expert support but not on a task that offered less assistance. Other study also found that age differences between high- and low-knowledge groups were comparable (Arbuckle, Vanderleck, Harsany, \& Lapidus, 1990). Some evidence suggests that schematic or contextual information improves readability among older adults (Miller, Cohen, \& Wingfield, 2006). Analysis of covariance (ANCOVA) was used to divide the groups by using score as the main variable and age as the covariate (Table 2). The result confirmed that a negative weak correlation emerged between the age and the score; the younger the age, the better the pre-test score they obtained (Fig. 3), but there was no interaction between the group and the age. This result affirmed that all groups have the same level in reading comprehension.

Table 13 Analysis of variance (ANOVA) type II result for immediate test, delayed test and pre-test

\begin{tabular}{lllll}
\hline Source & SS & Df & F-ratio & $p$ value \\
\hline Group & 0.911 & 2 & 0.3459 & 0.70799 \\
Age & 2.793 & 1 & 2.1200 & 0.14677 \\
Immediate test & 166.024 & 1 & 126.0261 & $<0.001^{* * *}$ \\
Pre-test & 5.022 & 1 & 3.8124 & 0.05211. \\
Residuals & 297.728 & 226 & & \\
\hline
\end{tabular}

Significant code: "****".001, "***".01, "**".05, "." .1," " 1 
Table 14 The combined mean for Material 2

\begin{tabular}{llll}
\hline Group & $n$ & Mean & SD \\
\hline C & 156 & 5.6859 & 1.6177 \\
E2 & 154 & 6.2338 & 1.2566 \\
E1 & 154 & 5.9481 & 1.3421 \\
\hline
\end{tabular}

Instruments

In this experiment, some of the reading materials were taken from the English for Information Technology book by Olejniczak, and the other was from the Teacher's Handbook. The reading materials used were entitled Data Storage, Channel of Communication, and Banana. Moreover, the Flesch Grade Level formula was applied for each material, and the result is shown in Table 3

\section{Procedures}

These experiments lasted 40 min per week for each session for each group. During the experiment, the learners did not receive any feedback from the teacher. They had to understand the reading materials by themselves. The complete sections in one session for each group are described in Fig. 4. In the second section of the experiment session, we are allowing students from all groups to open the reading material and allowing them to use a dictionary to help them understand words they did not know. However, during the test section, all the materials and dictionaries were closed.

\section{Analysis tools}

The ANCOVA analysis was used in this experiment to ensure that the age of the students did not affect the experiment result. The pre-test score was used as the basic guideline to create each group. We wanted to ensure that each group had the same level of reading comprehension. The immediate and delay tests were conducted as the values to measure the comprehension level of the students in each session. Both tests were used as the indicators of treatment among the groups. Lastly, Holm's sequentially rejective Bonferroni procedure was used as the post hoc analysis to rank up the groups.

\section{Results and discussion}

\section{Results}

This section was divided into three parts. Each part will show the analysis result for each material. Next is the discussion of the hypothesis that we have exposed earlier.

Table 15 Holm's sequentially rejective Bonferroni procedure results for Material 2

\begin{tabular}{|c|c|c|c|c|c|}
\hline Pair & Diff & $t$ value & Df & $p$ & \\
\hline C-E2 & -0.5479 & 2.7195 & 229 & 0.0070 & $C<E 2{ }^{* *}$ \\
\hline E2-E1 & -0.2857 & 1.4137 & 229 & 0.1588 & $\mathrm{E} 2=\mathrm{E} 1$ \\
\hline C-E1 & -0.2622 & 1.3013 & 229 & 0.1945 & $\mathrm{C}=\mathrm{E} 1$ \\
\hline
\end{tabular}




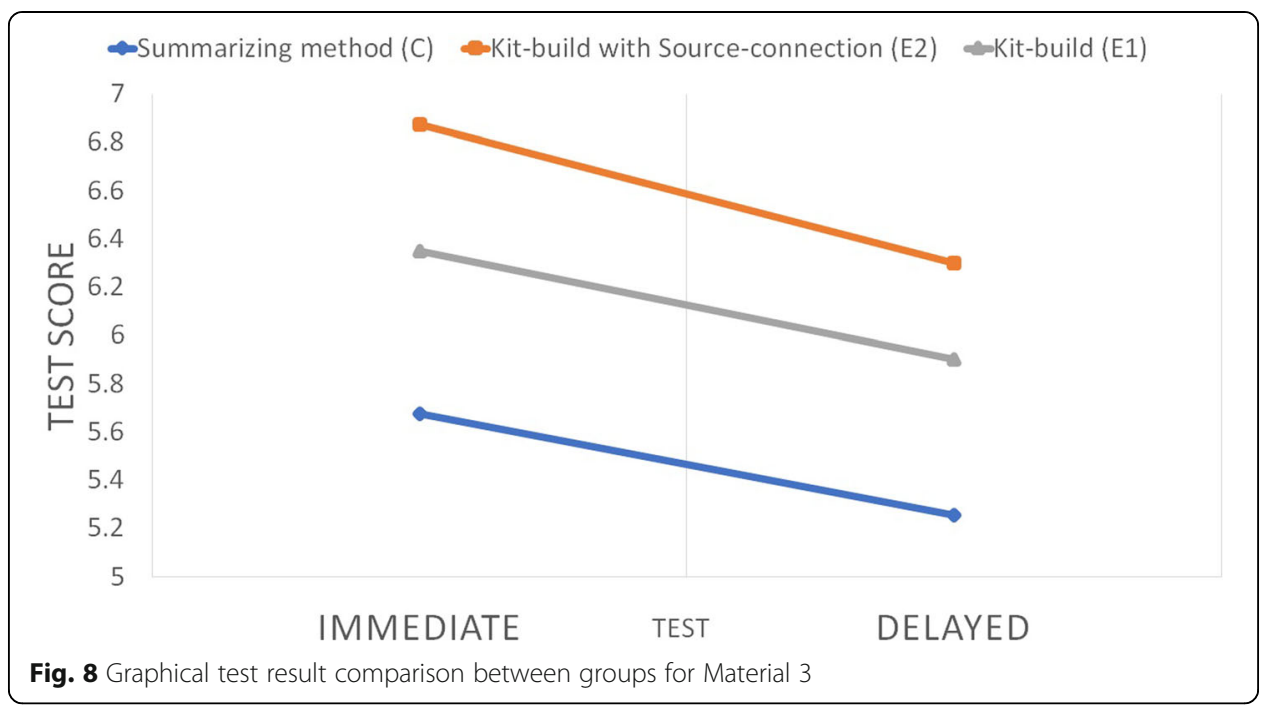

\section{Material 1 analysis}

The test results for Material 1 are shown in Fig. 5 and calculated in several steps. First, the mean analysis was conducted for each group for each test shown in Table 4.

Second, the ANCOVA was conducted to all groups by combining the immediate and delay tests as the variables named group, age and pre-test as the covariates. Because the data was unbalanced, the type II SS was used as the dependent measurement. The results in Table 5 showed that no interaction emerged between the group and the age but there was $(p<0.5)$ interaction between group score and pre-test; to investigate the result we are conducting a separate ANOVA analysis between immediate and delayed test to explain regarding this result. The results in Table 6 indicate that the pre-test is effective factors for immediate test and age can be ignored (see the correlation in Fig. 6), and the results in Table 7 indicate that immediate test and pre-test are affective factors for delayed test and we can ignore the age. Moreover, the age of the students in this session did not affect the scores of the learners, and significant differences $(p<.001)$ emerged among the groups.

However, the main effects of the treatments were observed for each group. Therefore, Holm's sequentially rejective Bonferroni procedure was applied by combining the mean of the immediate and delay test results for each group (Table 8), and the alpha level used was 0.05. Table 9 shows the results.

\section{Material 2 Analysis}

The test results for Material 2 are shown in Fig. 7 and also calculated in several steps. First, we conducted a mean analysis for each group for each test in Table 10.

Table 16 Mean of the immediate and delay tests of Material 3 in all groups

\begin{tabular}{llllll}
\hline Group & $N$ & Mean immediate & Mean delay & SD immediate & SD delay \\
\hline Summarizing method (C) & 78 & 5.679487 & 5.269231 & 2.028969 & 2.166289 \\
Kit-build (E1) & 77 & 6.350649 & 5.922078 & 1.636478 & 1.826459 \\
Kit-build with source-connection (E2) & 77 & 6.870130 & 6.298701 & 1.417472 & 1.953842 \\
\hline
\end{tabular}


Table 17 Analysis of covariance (ANCOVA) type II SS results for Material 3

\begin{tabular}{lllll}
\hline Source & SS & Df & F-ratio & $p$ value \\
\hline Pre-test & 181.62 & 1 & 59.542 & $<0.001^{* * *}$ \\
Age & 4.87 & 1 & 1.598 & 0.207 \\
Group & 97.39 & 2 & 15.954 & $<0.001^{* * *}$ \\
Pre-test: age & 5.07 & 1 & 1.663 & 0.198 \\
Pre-test: group & 16.93 & 2 & 2.775 & 0.063. \\
Age: group & 2.24 & 2 & 0.367 & 0.693 \\
Pre-test: age: group & 5.32 & 2 & 0.872 & 0.419 \\
Residuals & 1188.578 & 452 & & \\
\hline
\end{tabular}

Significant code: "***" .001, "**" .01, "** .05, ".. .1, " " 1

Second, ANCOVA was conducted to all groups of immediate and delay tests, and given that the data was unbalanced, the type II SS was used as the dependent measurement (Table 11). The result also suggested that no interaction emerged between the group and the age and between the group and pre-test that could affect the score. However, to ensure it, we also conducted the ANOVA analysis to support the result. The results in Table 12 indicate that only the group is the effective factors for immediate test, and the results in Table 13 indicate that only immediate test is the effective factor for the delayed test. Moreover, the age of the students in this session did not affect the scores of the learners, but there is a significant difference $(p<.01)$ of scores existed among the groups (Table 11).

However, the main effects of the treatments were observed for each group. Thus, Holm's sequentially rejective Bonferroni procedure was applied by combining the mean of the immediate and delay test results for each group in Table 14, and the alpha level used is 0.05 . Table 15 exhibits the results.

\section{Material 3 analysis}

The test results for Material 3 are shown in Fig. 8 and calculated in several steps. First, we conducted a mean analysis for each group for each test in Table 16.

Second, ANCOVA was conducted to all groups of the immediate and delay tests, and given that the data was unbalanced, the type II SS was used as the dependent measurement. The result suggested that there was no interaction that emerged between age and groups that effecting the score in Table 17. The ANOVA analysis was also conducted to investigate more regarding the result. Table 18 indicate that only group and pre-test are effective factors for the immediate test (see the correlation in Fig. 9) and Table 19 indicates that only immediate test and pre-test are effective factors for the delayed test.

Table 18 Analysis of variance (ANOVA) type II result for Immediate test and pre-test

\begin{tabular}{|c|c|c|c|c|}
\hline Source & SS & Df & F-ratio & $p$ value \\
\hline Group & 54.10 & 2 & 10.2856 & $<0.001^{* * *}$ \\
\hline Age & 2.04 & 1 & 0.7751 & 0.3796 \\
\hline Pre-test & 70.67 & 1 & 26.8719 & $<0.001^{* * *}$ \\
\hline Residuals & 596.99 & 227 & & \\
\hline
\end{tabular}

Significant code: "***". $001, " * * * .01, " * * " .05, " . " .1$, " " 1 


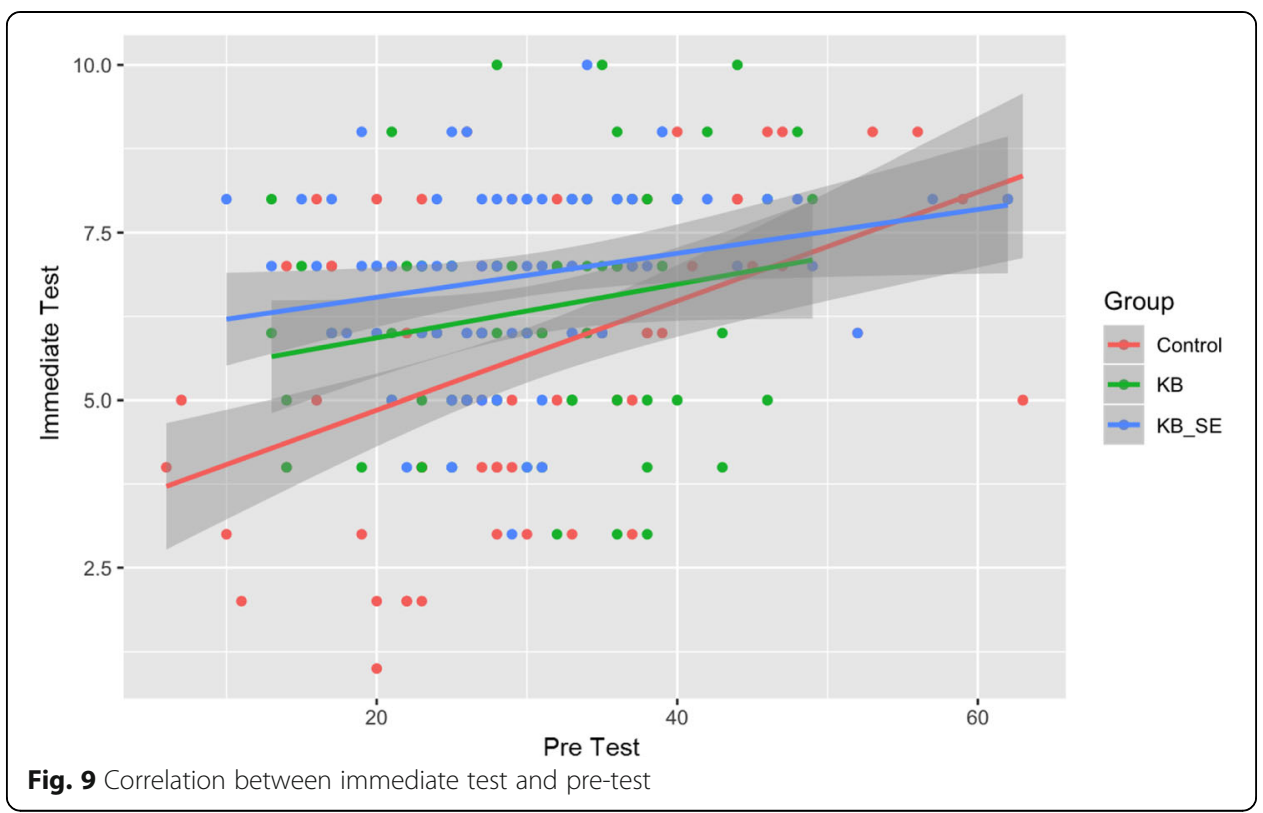

However, the main effects of the treatments were observed for each group; hence, Holm's sequentially rejective Bonferroni procedure was implemented by combining the mean of the immediate and delay test results for each group shown in Table 20, and the alpha level used is 0.05 . Table 21 shows the results.

\section{Discussion}

Most of the facts that we found in the experiment results were in line with our hypothesis. In the first session, the E2 score result was higher among all groups, followed by E1 in the second rank that has a higher score compared with $\mathrm{C}(p<.05)$ but has a lower score compared with E2 $(p<.05)$, and $\mathrm{C}$ has the lowest score among all the groups. In the second session, E2 was higher than $\mathrm{C}(p<.05)$ and had the same score with $\mathrm{E} 1(p>.05)$, and E1 had the same score with $\mathrm{C}(p>.05)$. This situation happens because no significant differences emerged between E2 and E1 and between E1 and C, but significant differences existed between E2 and C. In the third session, E2 and E1 had overachieved C, and no significant difference between E1 and E2. The answer to the research question would be E2 overachieved $\mathrm{C}$ in all the materials, but it overachieved $\mathrm{E} 1$ once, only twice were equal. We can confirm that age is not a factor in all the sessions, and in two sessions (sessions 1 and 3) the pre-test becoming the factor to get a better score in both immediate and delayed test. Learners with a better pre-test score would get a better score in both

Table 19 Analysis of variance (ANOVA) type II result for immediate test, delayed test and pre-test

\begin{tabular}{lllll}
\hline Source & SS & Df & F-ratio & $p$ value \\
\hline Group & 1.18 & 2 & 0.2787 & 0.757031 \\
Age & 1.05 & 1 & 0.4983 & 0.480988 \\
Immediate test & 306.00 & 1 & 144.9775 & $<0.001^{* * *}$ \\
Pre-test & 18.48 & 1 & 8.7566 & $0.003413^{* *}$ \\
Residuals & 474.82 & 226 & & \\
\hline
\end{tabular}

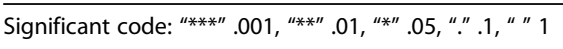


Table 20 The combined mean for Material 3

\begin{tabular}{llll}
\hline Group & $\mathrm{n}$ & Mean & $\mathrm{SD}$ \\
\hline $\mathrm{C}$ & 156 & 5.4744 & 2.1021 \\
E2 & 154 & 6.5844 & 1.7253 \\
E1 & 154 & 6.1364 & 1.7417 \\
\hline
\end{tabular}

immediate and delayed test. In addition to that, the use of KB-map with the source connection makes a difference in both immediate and delayed test from the summarizing method. This shows that kit-build with the source connection was better way from the summarizing method in this experiment.

Figure 10 shows the learners' way of learning by using the usual KB-map as a graphical strategy. The figure exhibits that the area is divided into two layers. A non-physical layer represents the mind of the learners, which cannot be seen, and the physical layer represents the outside world, which can be seen and interacted with. When learners read and comprehend the reading material, the information or knowledge is shaped into some kind of model in their mind or mental model, which can be called an understanding. After reading, they are asked to represent their understanding in a graphical map so that learners can directly see their understanding through the map. This activity aims at making learners realize or see their understanding. This research attempts to improve the learning process by assisting learners to fix their misunderstanding. This additional function is to encourage learners to make a reflection by making a connection between the reading material (the main source of information) and the proposition (understanding of learners in a graphical shape). Figure 11 shows that the additional function aims to urge learners to comprehend the reading material with their understanding of the mental model directly. In short, learners can make confirmation of their understanding of the reading material, repair their misunderstanding, and read the material one more time.

One of the failures that occur in graphical strategies is learners fail to make a correct proposition. This situation happens because they fail to understand the reading material. For the reduction of the understanding failure, the source-connection function was added to a graphical strategy, and this function aims to encourage learners to repair their misunderstanding. It intends to encourage learners to make confirmation by connecting the constructed proposition with the reading material. According to the fact found, adding the source-connection function to the kit-build concept map could better increase the learning activity in reading comprehension compared with the summarization method and also slightly better compared with the usual kit-build.

Table 21 Holm's sequentially rejective Bonferroni procedure result for Material 3

\begin{tabular}{llllll}
\hline Pair & Diff & $t$ value & Df & $p$ & \\
\hline C-E2 & -1.1101 & 4.0812 & 229 & $<0.001$ & $C<$ E2 *** \\
C-E1 & -0.6620 & 2.4339 & 229 & 0.0157 & C < E1 * \\
E2-E1 & -0.4481 & 1.6420 & 229 & 0.1020 & E2 $=$ E1 \\
\hline
\end{tabular}

Significant code: "***" $.001, "$ "**". $01, "$ "**".05, "." .1, " " 1 


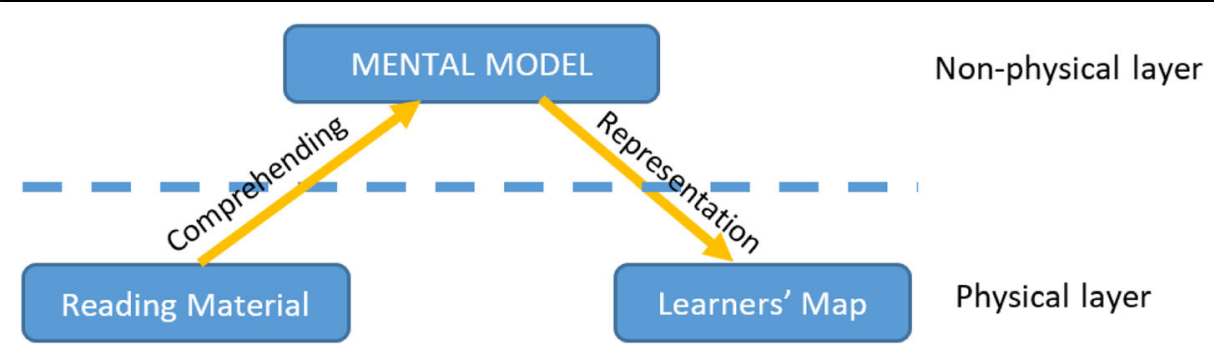

Fig. 10 Learner's thinking in usual KB-map

\section{Conclusion and future works}

Reading in English is a difficult task for EFL readers. Graphic strategies and comprehension monitoring are famous effective reading strategies. Some good readers use these strategies to understand the reading material, unlike the novice ones who are more passive. By promoting these actions, readers can act like good readers where they can confirm their understanding with the help of the system. This study proposes to add the source connection function to the KB-map method to facilitate learners to make a connection between concept maps and the reading materials for inducing comprehension monitoring. The result of the practical use of the KB-map with source connection shows that learners with the function achieve better performance than the ones with the traditional summarization method.

All the group in the second section of the session (summarizing for C Group, map construction for E1 group, map construction and map connection for E2 group) have the same opportunity to access the reading material. However, only the E2 group can confirm or clarify the proposition with the reading material. Most of the good readers using this kind of monitoring by themselves, unlike the novice ones who are more passive. Prompting learners to make a connection to the reading material shows a promising result when combined with the usual KB-map. Confirming their understanding of the reading material offers a new way to improve the kit-build concept map.

This study was conducted for 3 weeks with only $40 \mathrm{~min}$ in each session. In a general class situation, we cannot say that the abilities of learners are improved. We can only say that during this study, we are able to identify some positive learning effects, and this study offers a new point of view in the learning process of reading comprehension for EFL.

A deeper analysis of the learning process in the KB-map with source connection should be conducted in the future. This study measures not the process of

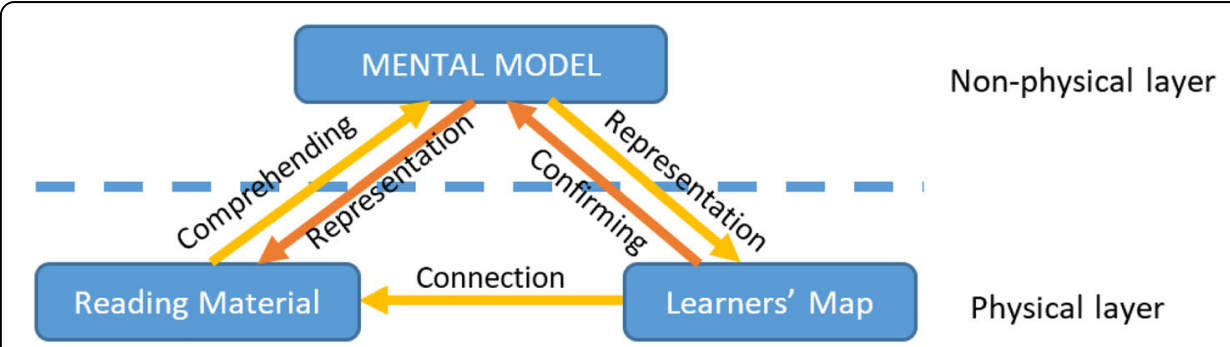

Fig. 11 Learners thinking in KB-map with source connection 
understanding but the result by questions about the content. Checking whether the proposal can change the comprehension process of EFL readers is also crucial to prove the hypothesis of this study. The analysis of operations in mapconstruction and map-connection and answers to the immediate and delay tests contributes to the revelation of the comprehension process of EFL readers with the KB-map with source-connection.

\section{Abbreviations}

ANCOVA: Analysis of covariance; ANOVA: Analysis of variance; C: Control group using the summarization method E1: Experimental group 1 using the usual KB-map; E2: Experimental group 2 using the KB-map with the sourceconnection function; EFL: English as foreign language; KB-map: Kit-build concept map; TOEIC: Test of English for international communication

\section{Acknowledgements}

I would like to thank Indonesia Endowment Fund for Education for supporting my study in Japan.

\section{Authors' contributions}

All authors participated in the research designs. ATQ conducted the experiments and preliminary analyzed the results. BSA analyzed the experiment results, executed the research under the supervision of $\mathrm{YH}$ and $\mathrm{TH}$, and drafted the manuscript. All authors read and approved the final manuscript.

\section{Funding}

Not applicable

Availability of data and materials

The authors declare that the supporting data is available in this link https://drive.google.com/drive/folders/1yYITYIOUAPXt75LB45pRhc7WLA3swhU? usp=sharing.

\section{Competing interests}

The authors declare that they have no competing interests.

Received: 18 June 2019 Accepted: 13 February 2020

Published online: 18 March 2020

\section{References}

Alessi, S. M., Anderson, T. H., \& Goetz, E. T. (1979). An investigation of lookbacks during studying. Discourse Processes, 2(3), 197-212.

Alkhateeb, M., Hayashi, Y., \& Hirashima, T. (2013). Experimental use of KB-map to support the reading comprehension of EFL. SIG-ALST-B301, 68, 1-5

Anderson, N. J. (2003). Metacognitive reading strategies increase L2 performance. The language teacher online, 27(7), 1-3.

Arbuckle, T. Y., Vanderleck, V. F., Harsany, M., \& Lapidus, S. (1990). Adult age differences in memory in relation to availability and accessibility of knowledge-based schemas. Journal of Experimental Psychology: Learning, Memory, \& Cognition, 305-315.

Baker, L. (1984). Cognitive monitoring in reading. Understanding reading comprehension.

Baker, L., \& Brown, A. L. (1984). Metacognitive skills and reading. In P. Pearson (Ed.), Handbook of reading research (pp. 353394). New York: Longman.

Baron, R., \& Schwartz, R. (1984). Traditional post organizers: a spatial learning strategy. In C. Holley \& D. Dansereau (Eds.), Spatial learning strategies: Techniques, applications, and related issues (pp. 275-189). New York: Academic Press.

Bernhardt, E. B. (1986). Cognitive processes in L2: an examination of reading. In J. Lantolf \& L. Labarca (Eds.), Research in second language learning: Focus on the classroom (pp. 35-51). Norwood: Ablex.

Bernhardt, E. B., \& Kamil, M. L. (1995). Interpreting relationships between L1 and L2 reading: consolidating the linguistic threshold and the linguistic interdependence hypotheses. Applied Linguistics, 15-34.

Bowey, J. A. (2005). Predicting individual differences in learning to read. In M. J. Snowling \& C. Hulme (Eds.), The Science of Reading: A Handbook (pp. 155-172). Malden: Blackwell Publishing.

Casanave, C. P. (1988). Comprehension monitoring in ESL reading: a neglected essential. TESOL Quarterly, 22(2), $283-302$.

Chang, K. E., Sung, Y. T., \& Chen, I. D. (2002). The effect of concept mapping to enhance text comprehension and summarization. The Journal of Experimental Education, 71(1), 5-23.

Chang, K. E., Sung, Y. T., \& Chen, S. (2001). Learning through computer-based concept mapping with scaffolding aid. Journal of Computer Assisted Learning, 17, 21-33.

Davies, M. (2011). Concept mapping, mind mapping and argument mapping: what are the differences and do they matter? High Educ, 62, 279-301. https://doi.org/10.1007/s10734-010-9387-6.

Dole, J. A., Duffy, G. G., Roehler, L. R., \& Pearson, P. D. (1991). Moving from the old to the new: research on reading comprehension instruction. Review of Educational Research, 61(2), 239-263 Retrieved from https://www.jstor.org/stable/1170536.

Dowhower, S. (1999). Supporting a strategic stance in the classroom: a comprehension framework for helping teachers help students to be strategic. The Reading Teacher, 52, 672-688.

Funaoi, H., Ishida, K., \& Hirashima, T. (2011). Comparison of kit-build and scratch-build concept mapping methods on memory retention (pp. 539-546). Chiang Mai: Proceedings of the 19th International Conference on Computers in. 
Hirashima, T., Yamasaki, K., Fukuda, H., \& Funaoi, H. (2015). Framework of kit-build concept map for automatic diagnosis and its preliminary use. Hiroshima: Research and Practice in Technology Enhanced Learning.

Liu, P.-L., Chen, C.-J., \& Chang, Y.-J. (2010). Effects of a computer-assisted concept mapping learning strategy on EFL college students' English reading comprehension. Computers \& Education ELSEVIER, 436-445.

McNamara, D. S. (2007). In D. S. McNamara (Ed.), Reading Comprehension Strategies: Theories, Intervensions, and Technology (p. xi). Mahwah, New Jersey.

Miller, L. M., Cohen, J. A., \& Wingfield, A. (2006). Contextual knowledge reduces demands on working memory during reading. Memory \& Cognition, 1355-1367.

Morrow, D., Leirer, V., Altieri, P., \& Fitzsimmons, C. (1994). When expertise reduces age differences in performance. American Psychological Association, 134-148.

Novak, J. (1990). Concept mapping: a useful tool for science education. Journal of Research in Science Teaching, 27, 939-949.

Pailai, J., Wunnasri, W., Yoshida, K., Hayashi, Y., \& Hirashima, T. (2017). The practical use of Kit-Build concept map on formative assessment. Research and Practice in Technology Enhanced Learning, 12, 20. https://doi.org/10.1186/s41039-017-0060-x.

Robinson, D., Katayama, A., \& Fan, A. (1996). Evidence for conjoint retention of information encoded from spatial adjunct displays. Contemporary Educational Psychology, 21, 221-239.

Snowling, M. J., \& Hulme, C. (2005). The Science of Reading: A Handbook. Malden: Blackwell Publishing.

van Dijk, T. \& Kintsch, W. (1983). Strategies of discourse comprehension. New York: Academic Press.

Wagoner, S. A. (1983). Comprehension monitoring: what it is and what we know about it. Reading Research Quarterly, 18(3), 328-346.

Wunnasri, W., Pailai, J., Hayashi, Y., \& Hirashima, T. (2018). Validity of kit-build method for assessment of learner-build map by comparing with manual methods. IEICE Transaction on Information and System, 1141-1150.

Yamasaki, K., Fukuda, H., Hirashima, T., \& Funaoi, H. (2010). Kit-build concept map and its preliminary evaluation. Malaysia: Proceedings of the 18th International Conference on Computers in Education.

Yang, C. C. (2003). A study of the effects of guided reading and writing directions on Taiwanese senior high school students English writing. Unpublished master thesis. Taiwan: National Changhua University of Education.

Yoshida, K., Sugihara, K., Nino, Y., Shida, M., \& Hirashima, T. (2013). Practical use of kit-build concept map system for formative assessment of learners' comprehension in a lecture. Proc. ICCE, 2013, 906-915.

\section{Publisher's Note}

Springer Nature remains neutral with regard to jurisdictional claims in published maps and institutional affiliations.

\section{Submit your manuscript to a SpringerOpen ${ }^{\circ}$ journal and benefit from:}

- Convenient online submission

- Rigorous peer review

- Open access: articles freely available online

- High visibility within the field

- Retaining the copyright to your article

Submit your next manuscript at $\boldsymbol{\nabla}$ springeropen.com 